\title{
Current Treatment Options for Cystic Fibrosis-Related Liver Disease
}

\author{
Katharina Staufer \\ Department of Visceral Surgery and Medicine, Inselspital, University Hospital Bern, 3010 Bern, Switzerland; \\ Katharina.Staufer@insel.ch; Tel.: +41-31-63-2-74-88
}

Received: 13 September 2020; Accepted: 11 November 2020; Published: 14 November 2020

check for updates

\begin{abstract}
Cystic Fibrosis-related liver disease (CFLD) has become a leading cause of morbidity and mortality in patients with Cystic Fibrosis (CF), and affects children and adults. The understanding of the pathogenesis of CFLD is key in order to develop efficacious treatments. However, it remains complex, and has not been clarified to the last. The search for a drug might be additionally complicated due to the diverse clinical picture and lack of a unified definition of CFLD. Although ursodeoxycholic acid has been used for decades, its efficacy in CFLD is controversial, and the potential of Cystic Fibrosis Transmembrane Conductance Regulator (CFTR) modulators and targeted gene therapy in CFLD needs to be defined in the near future. This review focuses on the current knowledge on treatment strategies for CFLD based on pathomechanistic viewpoints.
\end{abstract}

Keywords: cystic fibrosis-related liver disease; CFTR modulators; ursodeoxycholic acid; liver transplantation

\section{Introduction}

Cystic Fibrosis-related liver disease (CFLD) represents one of multiple optional organ manifestations of Cystic Fibrosis (CF), the most frequent fatal autosomal recessive disorder in Caucasians [1,2]. CF is a monogenic disease resulting from mutations within the cystic fibrosis transmembrane conductance regulator (CFTR) on chromosome 7 currently comprising $>2000$ different mutations [3].

CFTR encodes for a protein that is found i.a. in epithelial cells of lungs, sweat glands, pancreas, intestine, and liver. It belongs to the family of ATP-binding cassette (ABC) transporters (CFTR is alternately known as $\mathrm{ABC}$ subfamily $\mathrm{C}$ member 7 (ABCC7)) and functions as a cyclic adenosine monophosphate (cAMP)-dependent chloride channel that may open on the cell surface of epithelial cells. This chloride channel is necessary to maintain an alkaline $\mathrm{pH}$ and dilute fluid secretions [4] via a passive $\mathrm{Cl}^{-} / \mathrm{HCO}^{-}$anion exchange on exocrine epithelia along their electrochemical gradient $[5,6]$. Defects of CFTR may lead to dehydration of secretions and hyperviscous mucus, causing a multisystem disease with major affections of the respiratory, gastrointestinal, and hepatobiliary tract.

\section{Epidemiology and Clinical Presentation of CFLD}

Advances in patient care including solid organ transplantation have led to a strong increase of life expectancy in patients with CF with an estimated median survival of $>50$ years in patients born in the UK in 2000 and thereafter [7]. The recent introduction of CFTR-directed therapies may further prolong survival in the future.

Albeit lung disease remains the main cause of morbidity and mortality, the changing demographics of CF necessitate an increased focus also on other organ manifestations such as CFLD, which has become one of the leading causes of death among patients with CF [8].

However, the definition and diagnostic criteria of CFLD are subject to adjustments. In 1949 Pugsley and Spence first reported a case of liver cirrhosis in a 17-year old patient with CF [9]. Since then, 
knowledge has been gathered and refined over years. The definition of CFLD as suggested by Debray et al. in 2011 comprises the presence of significant findings in at least two of the four categories, i.e., physical examination (hepatomegaly and/or splenomegaly), liver function tests (elevated aspartate amino transaminase (AST), alanine amino transaminase (ALT), and gamma glutamyl transferase (GGT) at least at three consecutive determinations over 12 months after excluding other causes of liver disease), ultrasonography (signs of parenchymal liver disease, bile duct dilatation, and/or portal hypertension), and/or liver biopsy [10]. Recently, Koh et al. suggested a refined definition, considering an individual to have CFLD if there is radiologic or histologic evidence of cirrhosis or diffuse liver disease, or a positive finding is present in at least two of four categories, i.e., liver function tests, radiologic imaging, vibration controlled transient elastography, and/or noninvasive fibrosis biomarkers [11]. According to the latter definition of CFLD, also a higher amount of patients affected might be identified [11].

In summary, the clinical presentation of CFLD may include elevated liver enzymes, cholangiopathy, hepatic steatosis, portal hypertension including esophageal varices in about $70 \%$, as well as focal fibrosis and focal cirrhosis [12]. Risk factors for CFLD comprise male sex, presence of severe mutations, history of meconium ileus, exocrine pancreatic insufficiency, Pseudomonas aeruginosa, CF-related diabetes, and carrying the SERPINA $1 \mathrm{Z}$ Allele [13-16].

The prevalence of CFLD in children and adults ranges from 27 to $47 \%$ : In a longitudinal study by Colombo et al. including 177 consecutive patients with CF (mainly children) at their first presentation with a median follow up of 14 years, $27 \%$ of patients developed CFLD (incidence rate $1.8 \%$ ) diagnosed by either ultrasound or liver enzymes (steatosis not deemed as CFLD) [13]. Of these, $35 \%$ developed liver cirrhosis $(n=17 / 177=9.6 \%$, incidence rate $4.5 \%$ during a median period of 5 years after diagnosis of CFLD). In another longitudinal study by Lamireau et al. including 241 children with $C F$, the prevalence of CFLD (detected by ultrasound) was $41 \%$ after 12 years, and cirrhosis occurred in $7.9 \%(n=19 / 241)$ of patients at a median age of 10 years [14].

A study by Koh et al. investigated adult onset CFLD in a cohort of 36 patients without CFLD during childhood, who were followed for up to 38 years (median follow-up 24.5 years) [11]. The prevalence of CFLD was $47 \%$ at a median age of 36.6 years.

A further longitudinal population-based study by Toledano et al. analyzed data of 3417 children and adults with CF from the UK CF-registry and showed that the prevalence of CFLD (defined by elevated liver enzymes and/or abnormal liver ultrasound including steatosis) has increased during 2008 to 2013 [16]. Furthermore, mortality in patients with CFLD was more than doubled compared to patients without. Of note, liver cirrhosis was diagnosed at a median age of 19 years.

Thus, one the one hand, childhood-onset CFLD may progress over time, on the other hand also adulthood-onset CFLD may occur with higher age. Both observations may be a result of increased life expectancy of patients with CF. Whether childhood-onset (genetic factors more important) and adulthood-onset CFLD (environmental factors, secondary/tertiary causes more important) have the same pathogenesis in common remains to be elucidated.

Eventually, the definition of CFLD is not unified and is subject to changes due to the changing epidemiology as well as new discoveries that make diagnostic tools more sensitive and specific.

\section{Pathogenesis of CFLD}

The pathogenesis of CFLD is believed to be multifactorial and not clarified to the last [17]. Thinking of the whole clinical picture of CFLD that could be present, i.e., cholangiopathy, steatosis, liver fibrosis, focal cirrhosis, and portal hypertension (without cirrhosis being a mandatory requirement), we probably need to distinguish between primary, secondary, and tertiary causes that also might influence each other.

Primary causes for liver alterations, such as genetic factors affecting bile acid homeostasis and epithelial innate immunity of the bile ducts, secondary causes such as CF-related diabetes (CFRD), exocrine pancreatic insufficiency, intestinal inflammation, changes in the gut microbiome, as well as 
tertiary causes such as antibiotics, immunosuppressive medication, and high fat diet might coin the clinical presentation of CFLD.

CFTR mutations are classified as class I, II, III, IV, V, and VI depending on the underlying CFTR defect. Class I mutations affect biosynthesis of CFTR and thereby lead to the absence of a functional CFTR protein. Class II mutations (including the most common CFTR mutation deletion of a phenylalanine at position 508 (F508del)) interfere with protein maturation, why CFTR comes up misfolded and causes a CFTR trafficking defect. Class III mutations lead to a defective $\mathrm{Cl}-/ \mathrm{HCO}^{-}$-channel regulation. Class IV mutations cause a decreased $\mathrm{Cl}^{-} / \mathrm{HCO}^{-}$-channel conductance, Class $\mathrm{V}$ mutations cause a reduced synthesis of CFTR, and Class VI mutations lead to CFTR membrane stability [2].

CFTR genotype-phenotype correlations, however, are generally weak due to different mutation penetrance in various organs. More severe mutations such as classes I, II, and III present with higher morbidity and mortality and correlate well with pancreatic insufficiency $(>95 \%)$, meconium ileus ( $>20 \%)$, higher sweat chloride levels $(\geq 60 \mathrm{mmol} / \mathrm{L})$, younger age $(<1$ year) at diagnosis, and liver disease (in 3-5\%) [18].

In the liver, CFTR is expressed in the apical membrane of cholangiocytes, but not hepatocytes [19], and constitutes a major determinant of bile secretion. Dysfunctional or lacking CFTR protein leads to a disrupted $\mathrm{Cl}^{-}$- and $\mathrm{HCO}^{-}$secretion, and thus a hyperviscous and more acidic bile (including aberrant bile acid composition and increased concentration of toxic bile acids). The resulting ductular biliary obstruction leads to local inflammation resulting in the picture of sclerosing cholangitis as well as portal inflammation, which may cause a focal fibrosis in the first place, but later multilobular fibrosis and cirrhosis. Furthermore, as recently described by Fiorotto et al., CFTR is additionally involved in the control of biliary epithelial inflammation and permeability in a mouse model [20]. This is facilitated by controlling the activation of the tyrosine kinase Src, a protooncogene, which in turn regulates toll-like receptor 4 (TLR-4)—responses to gut-derived endotoxins. Additionally, aberrant TLR-4 activation decreases the epithelial barrier function leading to a back-diffusion of toxic bile acids again causing peribiliary inflammation and fibrosis [20]. Additionally, the same researchers recently postulated an auto-inflammatory component in the pathogenesis of CFLD as a result of aberrant activation of the innate immune system. This may be mediated via an increased basal NF-kB activation found in human F508del cholangiocytes, which in turn actively secrete pro-inflammatory chemokines known to attract neutrophils. Furthermore, F508del cholangiocytes showed increased responsiveness to endotoxins, as well as Src kinase activation and toll-like receptor 4 (TLR4) phosphorylation leading to local inflammation [21].

Additionally, not only CFTR defects may cause CFLD, but also the SERPINA-1Z-allele has been identified as a modifier gene for the development of CFLD [15]. In patients carrying the Z-allele the $\alpha 1$-antitrypsin variant accumulates in hepatocytes and cholangiocytes [22], which could lead to further endoplasmatic reticulum stress and predispose cholangiocytes to injury of other causes [23]. A recent in silico analysis identified further candidate modifier genes potentially involved in CFLD (i.e., Solute carrier family 33 acetyl-coenzyme A transporter member 1 (SLC33A1), glycoprotein NMB (GPNMB), neutrophil cytosolic Factor 2 (NCF2), RAS guanyl nucleotide-releasing protein 1 (RASGRP1), lectin galactosidase-binding soluble 3 (LGALS3), and protein-tyrosine phosphatase nonreceptor-type 13 (PTPN13)) [24].

A clear definition of CFLD, as well as unraveling the pathomechanism that underlies the evolution of CFLD, including the consideration of its clinical characteristics and severity determine the development of efficacious treatments.

\section{General Treatment Recommendations for CFLD}

Treatment of CFLD should be in the hand of an experienced, multidisciplinary team [25]. It comprises two major aspects, firstly, treating the underlying liver disease itself, and secondly, managing nutritional therapy, as well as portal hypertension and decompensated cirrhosis, both possible results of the 
underlying liver disease. Liver transplantation may be the ultimate treatment in patients with end-stage liver disease.

Treating the underlying liver disease to date mainly includes the administration of ursodeoxycholic acid (UDCA). Current knowledge on UDCA in CFLD is described in Section 5. The potential of CFTR modulators, gene therapy and future treatment options is described in Sections 6-8.

Nutritional therapy with regard to CFLD mainly aims at improving the nutritional status of the patient by optimizing dietary intake of calories (especially protein), pancreatic enzyme replacement, supplementation of fat-soluble vitamins A, D, E, K, and insulin treatment in patients with CFRD. It may also include the correction of deficiencies of essential fatty acids, carnitine and choline since an association with liver steatosis has been postulated $[25,26]$.

The management of portal hypertension in CFLD (especially adulthood CFLD) includes endoscopic screening for gastroesophageal varices and consecutive band ligation or sclerotherapy as primary or secondary bleeding prophylaxis [27]. Unselective beta-blocker therapy with propranolol or carvedilol might be used in order to prevent bleeding [27], but should be used with caution in patients with reactive airway disease, since randomized controlled trials in patients with $\mathrm{CF}$ are currently lacking. Other complications of portal hypertension such as ascites, spontaneous bacterial peritonitis and hepatic encephalopathy should be treated according to current guidelines on patients with decompensated liver cirrhosis [28]. However, it needs to be taken into account that portal hypertension in patients with CFLD often occurs in the absence of liver cirrhosis and the presence of preserved liver function [29]. Non-cirrhotic portal hypertension in CFLD was found to be associated with portal branch venopathy in small case series [30,31]. In these patients, transjugular intrahepatic portosystemic shut can be a therapeutic option.

Unified criteria for the indication and timing of liver transplantation for CFLD have not been established so far. However, in patients with CF, deterioration of nutritional status and pulmonary function should be given special consideration [10]. Since the median survival time has been increasing, liver transplantation for CFLD might become more frequent in the future.

\section{Effects of Ursodeoxycholic Acid on CFLD}

As according to the Best Practice Guidance for the Diagnosis and Management of CFLD, UDCA should be commenced as soon as the diagnosis of CFLD has been made at a dose of $20 \mathrm{mg} / \mathrm{kg}$ body weight (BW) in order "to delay the progression of the disease" [10].

However, although UDCA has been repeatedly investigated as treatment for CFLD since the 1990s [32,33], until now its efficacy in CFLD has remained controversial. Several small prospective case series and larger retrospective registry data mainly could demonstrate a significant positive effect on liver enzymes, however, randomized controlled trials assessing hard endpoints such as improvement in liver histology, mortality or liver transplant free survival are still lacking but remain crucial. Furthermore, the interpretation of the findings is frequently limited due to the lack of a homogenous definition of CFLD and uniform assessment of liver disease severity. Table 1 summarizes the current knowledge on UDCA in CFLD-treatment.

The lacking evidence is made obvious by a Chochrane review from 2017, which analyzed the present evidence on UDCA in terms of improvement of liver function, risk reduction for the development of chronic liver disease, and improvement in general outcomes in CF [34]. All randomized controlled trials that applied UDCA for at least three months compared with placebo or no additional treatment were considered. Of 12 identified trials only three trials comprising 118 participants dating back to the 1990s were included [35,36], applying 10-20 mg/kg body weight of UDCA for up to 12 months. No significant effect of UDCA could be found, not at least also due to the fact that patient numbers analyzed were very small, and length of treatment with UDCA might have been too short. A more recent longitudinal cohort study by Toledano et al. (already mentioned above) investigating $>3000$ patients reported a positive association of UDCA with prolonged overall survival in patients 
without cirrhosis (HR 0.50, 95\% CI 0.36-0.69, $p<0.0001$ ) in contrast to patients with cirrhotic disease (HR 1.19, 95\% CI 0.46-3.10, $p=0.71$ ) [16], suggesting a positive effect in patients with mild CFLD.

In summary, although the use of UDCA in CFLD has become a standard treatment, the scientific basis for this requires more reliable data especially for efficacy endpoints in middle-and long-term use. Nevertheless, UDCA appears to be beneficial, especially when started early and against the background of lacking therapeutic alternatives.

\section{Effects of CFTR Modulators on CFLD}

CFTR modulators are small molecules, which directly target CFTR and thereby partly restore altered CFTR protein function. Their development has presented a breakthrough in the treatment of $\mathrm{CF}$, however, their effect on CFLD remains widely unclear.

Generally, we need to distinguish between CFTR potentiators and correctors, as well as stabilizers, amplifiers and read-through agents, which may be given in supplement to the first two. Potentiators keep the CFTR channel open so that chloride transport is ensured, correctors may help to ensure correct CFTR protein folding so that CFTR is able to traffic to the cell surface and remains there longer. In addition, stabilizers promote CFTR maturation and plasma membrane stability, and thereby increase the half-life of the CFTR protein, amplifiers may increase the amount of CFTR protein that is produced by the cell, and read-through agents may bypass premature termination codons. Currently, only CFTR potentiators and correctors are readily available to patients.

The CFTR modulator which was developed first was ivacaftor (VX-770, Kalydeco $\left.{ }^{\circledR}\right)$, a CFTR potentiator. The small molecule treating the class III mutation G551D gained FDA approval in 2012. Later it became apparent that it also works in other class III and IV mutations (gating, residual function, splice and conduction mutations). The second medication which was approved by the FDA in 2015 was a CFTR modulator combination of ivacaftor with lumacaftor (VX-770/VX-809, Orkambi ${ }^{\circledR}$ ) to treat homozygous F508del mutation (protein processing mutation). However, its effect on improvement of FEV1 and reduction of pulmonary exacerbations was only small to modest, probably also due to antagonistic effects of VX-809 and VX-770. In February 2018 tezacaftor, another corrector, was approved in combination with ivacaftor (VX-661/VX-770, Symdeko ${ }^{\circledR}$ ) for patients with at least one F508del mutation (protein processing, residual function, splice mutations), bearing the advantage of lesser side effects and drug interactions than the combination of lumafactor/ivacaftor.

Ivacaftor, lumacaftor, and tezacaftor all are deemed as first generation CFTR modulators. Although their development represented a breakthrough in the management of patients with $\mathrm{CF}$, treatment with the first generation CFTR modulators either cannot target frequent mutations, or their efficacy is limited. This has highlighted the need for further drug evolution and led to the development of the next generation CFTR corrector VX-445/ elexacaftor, which is able to correct an additional defect in the formation of the F508del-CFTR protein. Hence, a drug was approved as a triple combination of ivacaftor, tezacaftor, and elexacaftor (VX-770/Vx-661/VX-445, Trikafta ${ }^{\mathrm{TM}}$ ) by the FDA in October 2019. Trikafta $^{\mathrm{TM}}$ is approved for patients with at least one F508del mutation and, in contrast to its predecessors, shows higher efficacy and is estimated to be able to treat about $90 \%$ of the CF population [50-52]. Table 2 presents an overview on approved CFTR modulators and their effects.

Further CFTR modulators currently are being tested in phase 1 or 2, such as the CFTR potentiators VX-561 (deuterated ivacaftor) and ABBV-3067, the CFTR correctors ABBV-2222, and VX-121, the CFTR amplifiers fPTI-428, and PTI-CH, and the read-through agent ELX-02 [53]. 
Table 1. Ursodeoxycholic Acid as Treatment for Cystic Fibrosis-Related Liver Disease.

\begin{tabular}{|c|c|c|c|c|c|c|c|c|c|c|}
\hline Author & Year & Study Design & $\begin{array}{l}\text { Number of } \\
\text { Patients } \\
\text { with CFLD }\end{array}$ & $\begin{array}{c}\text { Mean/Median } \\
\text { Age (y) }\end{array}$ & $\%$ Male & $\begin{array}{c}\text { Definition of } \\
\text { CFLD/Inclusion } \\
\text { Criteria }\end{array}$ & $\begin{array}{l}\text { UDCA Dosage } \\
\text { (per kg Body } \\
\text { Weight/Day) }\end{array}$ & $\begin{array}{l}\text { Treatment } \\
\text { Duration } \\
\text { (in Months) }\end{array}$ & Side Effects & $\begin{array}{l}\text { Relevant } \\
\text { Findings }\end{array}$ \\
\hline $\begin{array}{c}\text { Cotting et al. } \\
\text { [32] }\end{array}$ & 1990 & $\begin{array}{l}\text { Prospective } \\
\text { cohort study } \\
\text { without } \\
\text { comparison } \\
\text { group }\end{array}$ & 8 & 18.0 & 62.5 & $\begin{array}{l}\text { - chronic cholestasis } \\
\text { manifested by raised } \\
\text { liver enzyme activities } \\
\text { over at least one year, } \\
\text { associated with } \\
\text { abnormal of liver size, } \\
\text { liver surface, and } \\
\text { homogeneity of the } \\
\text { parenchyma in US. } \\
\text { - absence of surgically } \\
\text { treatable obstruction as } \\
\text { a cause of cholestasis } \\
\text { shown by US or } \\
\text { hepatobiliary } \\
\text { scintigraphy with } \\
\text { 99mTc labeled } \\
\text { N-(2,6-diethyl-3-iodo- } \\
\text { phenylcarbamoylmethyl)- } \\
\text { iminodiacetate, or both. }\end{array}$ & $15-20 \mathrm{mg}$ & 6 & none & $\begin{array}{c}\text { decrease in AST } \\
(p<0.005) \text { and } \\
\text { ALT }(p<0.001) \\
\text { BW increase } \\
(p<0.0001) \\
\text { increase in muscle } \\
\text { mass }(p<0.05)\end{array}$ \\
\hline $\begin{array}{c}\text { Colombo et al. } \\
\text { [33] }\end{array}$ & 1990 & $\begin{array}{l}\text { Prospective } \\
\text { cohort study } \\
\text { without } \\
\text { comparison } \\
\text { group }\end{array}$ & 9 & 10.7 & 66.0 & $\begin{array}{l}\text { - presence of firm } \\
\text { hepatomegaly and } \\
\text { - persistent increase in } \\
\text { standard liver function } \\
\text { test values during a } \\
\text { 2-year period }\end{array}$ & $\begin{array}{c}10-15 \mathrm{mg} \\
\text { (plus taurine } 30 \\
\mathrm{mg} / \mathrm{kg} \mathrm{BW} \text { ) }\end{array}$ & 6 & $\begin{array}{c}\text { minor } \\
\text { abdominal } \\
\text { discomfort } \\
\text { in one } \\
\text { patient }\end{array}$ & $\begin{array}{c}\text { decrease in ALT } \\
\text { and GGT } \\
(p<0.01) \text { and AP } \\
(p<0.05)\end{array}$ \\
\hline $\begin{array}{c}\text { Colombo et al. } \\
\text { [37] }\end{array}$ & 1992 & $\begin{array}{l}\text { Prospective } \\
\text { cohort study } \\
\text { without } \\
\text { comparison } \\
\text { group }\end{array}$ & $\begin{array}{c}13 \\
\text { (of these } 9 \\
\text { patients } \\
\text { were already } \\
\text { included in } \\
\text { [24]) }\end{array}$ & 11.0 & 69.2 & $\begin{array}{l}\text { - presence of clinical, } \\
\text { biochemical and } \\
\text { abnormalities in US }\end{array}$ & $15-20 \mathrm{mg}$ & 10 to 12 & none & $\begin{array}{l}\text { improvement in } \\
\text { canalicular } \\
\text { excretory function } \\
\text { and biliary } \\
\text { drainage } \\
\text { (hepatobiliary } \\
\text { scintigraphy with } \\
\text { 99mTc-labeled } \\
\text { trimethyl-bromo- } \\
\text { iminodiacetic } \\
\text { acid) }\end{array}$ \\
\hline
\end{tabular}


Table 1. Cont.

\begin{tabular}{|c|c|c|c|c|c|c|c|c|c|c|}
\hline Author & Year & Study Design & $\begin{array}{l}\text { Number of } \\
\text { Patients } \\
\text { with CFLD }\end{array}$ & $\begin{array}{c}\text { Mean/Median } \\
\text { Age (y) }\end{array}$ & $\%$ Male & $\begin{array}{c}\text { Definition of } \\
\text { CFLD/Inclusion Criteria }\end{array}$ & $\begin{array}{l}\text { UDCA Dosage } \\
\text { (per kg Body } \\
\text { Weight/Day) }\end{array}$ & $\begin{array}{c}\text { Treatment } \\
\text { Duration } \\
\text { (in Months) }\end{array}$ & Side Effects & $\begin{array}{l}\text { Relevant } \\
\text { Findings }\end{array}$ \\
\hline $\begin{array}{c}\text { Galabert et al. } \\
\text { [38] }\end{array}$ & 1992 & $\begin{array}{l}\text { Prospective } \\
\text { cohort study } \\
\text { without } \\
\text { comparison } \\
\text { group }\end{array}$ & 22 & 15.3 & 77.3 & $\begin{array}{c}\text { - existence of chronic } \\
\text { cholestasis assessed by a } \\
\text { persistent } \\
\text { (>1 year) and significant } \\
\text { increase }(>2 \text { upper } \\
\text { normal limit) of GGT, } \\
\text { ALP and } 5^{\prime} \text {-nucleotidase } \\
\text { - presence of firm } \\
\text { hepatomegaly, and } \\
\text { - abnormal findings on US } \\
\text { (increased size, } \\
\text { nonhomogeneous } \\
\text { echogenicity, irregular } \\
\text { surface) }\end{array}$ & $10-20 \mathrm{mg}$ & 12 & none & $\begin{array}{c}\text { decrease in ALT } \\
(p<0.002), \\
\text { AST }(p<0.01), \\
\text { GGT }(p<0.001) \\
\text { AP }(p<0.001)\end{array}$ \\
\hline $\begin{array}{l}\text { Colombo et } \\
\text { al. [39] }\end{array}$ & 1992 & $\begin{array}{l}\text { Prospective } \\
\text { cohort study } \\
\text { without } \\
\text { comparison } \\
\text { group }\end{array}$ & 9 & 11.8 & 77.8 & $\begin{array}{l}\text { - progressive liver disease } \\
\text { was documented over a } \\
2 \text {-yr period in } \\
\text { all patients from clinical, } \\
\text { biochemical and } \\
\text { echographical } \\
\text { abnormalities }\end{array}$ & $\begin{array}{c}5,10 \text {, and } 15 \mathrm{mg} \\
\text { in a replicated } \\
\text { latin square } \\
\text { design for } 2 \mathrm{mo}, \\
\text { followed by } 20 \\
\mathrm{mg} \text { for } 2 \mathrm{mo}\end{array}$ & $\begin{array}{c}4 \\
(2 \text { mo plus } 2 \\
\text { mo })\end{array}$ & n.r. & $\begin{array}{l}\text { biochemical } \\
\text { improvement in } \\
\text { serum liver } \\
\text { enzymes was } \\
\text { significantly } \\
\text { greater with } \\
\text { higher doses }\end{array}$ \\
\hline $\begin{array}{c}\mathrm{O}^{\prime} \text { Brien et al. } \\
{[40]}\end{array}$ & 1996 & $\begin{array}{c}\text { Posthoc } \\
\text { analysis of } \\
\text { randomized } \\
\text { controlled trial }\end{array}$ & $\begin{array}{l}6 \text { vs. } 6 \\
\text { without } \\
\text { UDCA }\end{array}$ & n.r. & n.r. & $\begin{array}{c}\text { - hepatomegaly (liver } \\
\text { span in excess of } 12 \mathrm{~cm} \text { ) } \\
\text { and splenomegaly or } \\
\text { both, confirmed by US } \\
\text { and } \\
\text { - abnormal liver } \\
\text { biochemistry (GGT >50 } \\
\text { IU/l, 5'nucleotidase > } 15 \\
\text { IU/I) or } \\
\text { - both for at least } 6 \text { mo }\end{array}$ & $20 \mathrm{mg}$ & 6 & n.r. & $\begin{array}{c}\text { decrease in AST } \\
\text { GGT, and } \\
5^{\prime} \text { nucleosidase } \\
(p<0.05)\end{array}$ \\
\hline
\end{tabular}


Table 1. Cont

\begin{tabular}{|c|c|c|c|c|c|c|c|c|c|c|}
\hline Author & Year & Study Design & $\begin{array}{c}\text { Number of } \\
\text { Patients } \\
\text { with CFLD }\end{array}$ & $\begin{array}{c}\text { Mean/Median } \\
\text { Age (y) }\end{array}$ & \% Male & $\begin{array}{c}\text { Definition of } \\
\text { CFLD/Inclusion Criteria }\end{array}$ & $\begin{array}{l}\text { UDCA Dosage } \\
\text { (per kg Body } \\
\text { Weight/Day) }\end{array}$ & $\begin{array}{l}\text { Treatment } \\
\text { Duration } \\
\text { (in Months) }\end{array}$ & Side Effects & $\begin{array}{l}\text { Relevant } \\
\text { Findings }\end{array}$ \\
\hline $\begin{array}{l}\text { Colombo } \\
\text { et al. [35] }\end{array}$ & 1996 & $\begin{array}{l}\text { Multicentre, } \\
\text { double-blind, } \\
\text { placebo-controlled } \\
\text { trial }\end{array}$ & d & 13.8 & 70.9 & $\begin{array}{l}\text { - presence of } \\
\text { hepatomegaly, confirmed } \\
\text { by US (increased liver } \\
\text { size, nonhomogeneous } \\
\text { echogenic pattern, and } \\
\text { irregular surface), and the } \\
\text { presence of abnormal } \\
\text { liver biochemistries } \\
\text { (serum transaminases, } \\
\text { GGT) of at least } 1 \text { year's } \\
\text { duration. } \\
\text { - presence of serum } \\
\text { transaminase and GGT } \\
\text { levels exceeding } 1.5 \text { times } \\
\text { the upper limit of normal } \\
\text { on at least three } \\
\text { determinations over the } \\
\text { year }\end{array}$ & $\begin{array}{c}15-20 \mathrm{mg} \\
\text { (+ } 30 \mathrm{mg} / \mathrm{kg} \mathrm{BW} \\
\text { taurine) } \\
\text { UDCA + taurine } \\
\text { vs. UDCA + } \\
\text { placebo vs. } \\
\text { placebo + } \\
\text { taurine vs. } \\
\text { double placebo }\end{array}$ & 12 & $\begin{array}{l}\text { transient } \\
\text { diarrhea, } \\
\text { mild and } \\
\text { transient } \\
\text { abdominal } \\
\text { pain }\end{array}$ & $\begin{array}{l}\text { decrease in GGT } \\
\quad(p=0.025)\end{array}$ \\
\hline $\begin{array}{l}\text { Lepage et al. } \\
\text { [36] }\end{array}$ & 1997 & $\begin{array}{l}\text { Randomized } \\
\text { double-blind } \\
\text { placebo-controlled } \\
\text { crossover } \\
\text { study }\end{array}$ & d & 11.9 & 68.4 & $\begin{array}{c}\text { - abnormal findings on at } \\
\text { least two liver function } \\
\text { tests (ALT, AST, GGT) } \\
\text { and } \\
\text { - an abnormal finding on } \\
\text { US or liver biopsy or both }\end{array}$ & $\begin{array}{c}15 \mathrm{mg} ; \\
\text { increased to } 30 \\
\text { mg if less than } \\
50 \% \text { decrease of } \\
\text { ALT or AST or } \\
\text { both within } 2 \\
\text { mo was } \\
\text { achieved } \\
\text { (UDCA vs } \\
\text { placebo) }\end{array}$ & $\begin{array}{c}6 \\
(6 \mathrm{mo} \\
\text { placebo, } 6 \\
\text { mo UDCA; } \\
13 \text { of } 19 \text { pts } \\
\text { followed for } \\
25 \mathrm{mo})\end{array}$ & none & $\begin{array}{c}\text { decrease in ALT } \\
(p<0.01) \text { and } \\
\text { GGT }(p<0.001)\end{array}$ \\
\hline
\end{tabular}


Table 1. Cont.

\begin{tabular}{|c|c|c|c|c|c|c|c|c|c|c|}
\hline Author & Year & Study Design & $\begin{array}{l}\text { Number of } \\
\text { Patients } \\
\text { with CFLD }\end{array}$ & $\begin{array}{l}\text { Mean/Median } \\
\text { Age (y) }\end{array}$ & $\%$ Male & $\begin{array}{c}\text { Definition of } \\
\text { CFLD/Inclusion Criteria }\end{array}$ & $\begin{array}{l}\text { UDCA Dosage } \\
\text { (per kg Body } \\
\text { Weight/Day) }\end{array}$ & $\begin{array}{l}\text { Treatment } \\
\text { Duration } \\
\text { (in Months) }\end{array}$ & Side Effects & $\begin{array}{l}\text { Relevant } \\
\text { Findings }\end{array}$ \\
\hline $\begin{array}{c}\text { Van de } \\
\text { Meeberg et al. } \\
\text { [41] }\end{array}$ & 1997 & $\begin{array}{l}\text { Randomized } \\
\text { trial (low dose } \\
\text { vs. high dose } \\
\text { UDCA) }\end{array}$ & 30 & 18.3 & 64.7 & $\begin{array}{l}\text { - disturbed liver } \\
\text { biochemistry and the } \\
\text { presence of abnormalities } \\
\text { in US or esophageal } \\
\text { varices on endoscopy at } \\
\text { two separate occasions at } \\
\text { least } 3 \text { mo apart } \\
\text { - two or more of the } \\
\text { following biochemical } \\
\text { variables > } 1.5 \text { the upper } \\
\text { normal limit: bilirubin, } \\
\text { AP, GGT, ALT, AST, or } \\
\text { - if one of these factors > } \\
1.5 \text { the upper normal limit } \\
\text { in combination with the } \\
\text { presence of splenomegaly } \\
\text { or esophageal varices }\end{array}$ & $10 \mathrm{mg}$ vs. $20 \mathrm{mg}$ & 12 & $\begin{array}{l}\text { severe } \\
\text { pruritus in } 2 \\
\text { pts required } \\
\text { treatment } \\
\text { stopp }\end{array}$ & $\begin{array}{c}\text { - decrease in ALT } \\
(p<0.02) \text { and } \\
\text { GGT }(p<0.004) \\
\text { - high dose UDCA } \\
\text { induces a better } \\
\text { response in liver } \\
\text { enzymes }\end{array}$ \\
\hline $\begin{array}{l}\text { Lindblad et } \\
\text { al. [42] }\end{array}$ & 1998 & $\begin{array}{l}\text { Prospective } \\
\text { cohort study } \\
\text { without } \\
\text { comparison } \\
\text { group }\end{array}$ & 10 & 17.6 & 60.0 & $\begin{array}{l}\text { - probable or proven } \\
\text { cirrhosis on liver biopsy, } \\
\text { including fibrosis with } \\
\text { extensive bridging and/or } \\
\text { signs of irregularities of } \\
\text { the intrahepatic bile ducts } \\
\text { at endoscopic retrograde } \\
\text { cholangiography }\end{array}$ & $10-15 \mathrm{mg}$ & 24 & none & $\begin{array}{c}\text { - decrease in ALT } \\
\text { and AST }(p<0.05) \\
\text { - decrease in GGT } \\
\text { only significant } \\
\text { after } 12(p<0.05) \\
\text { but not } 24 \text { mo } \\
\text { - decrease in } \\
\text { immunoglobuline } \\
\text { G }(p<0.01)\end{array}$ \\
\hline
\end{tabular}


Table 1. Cont.

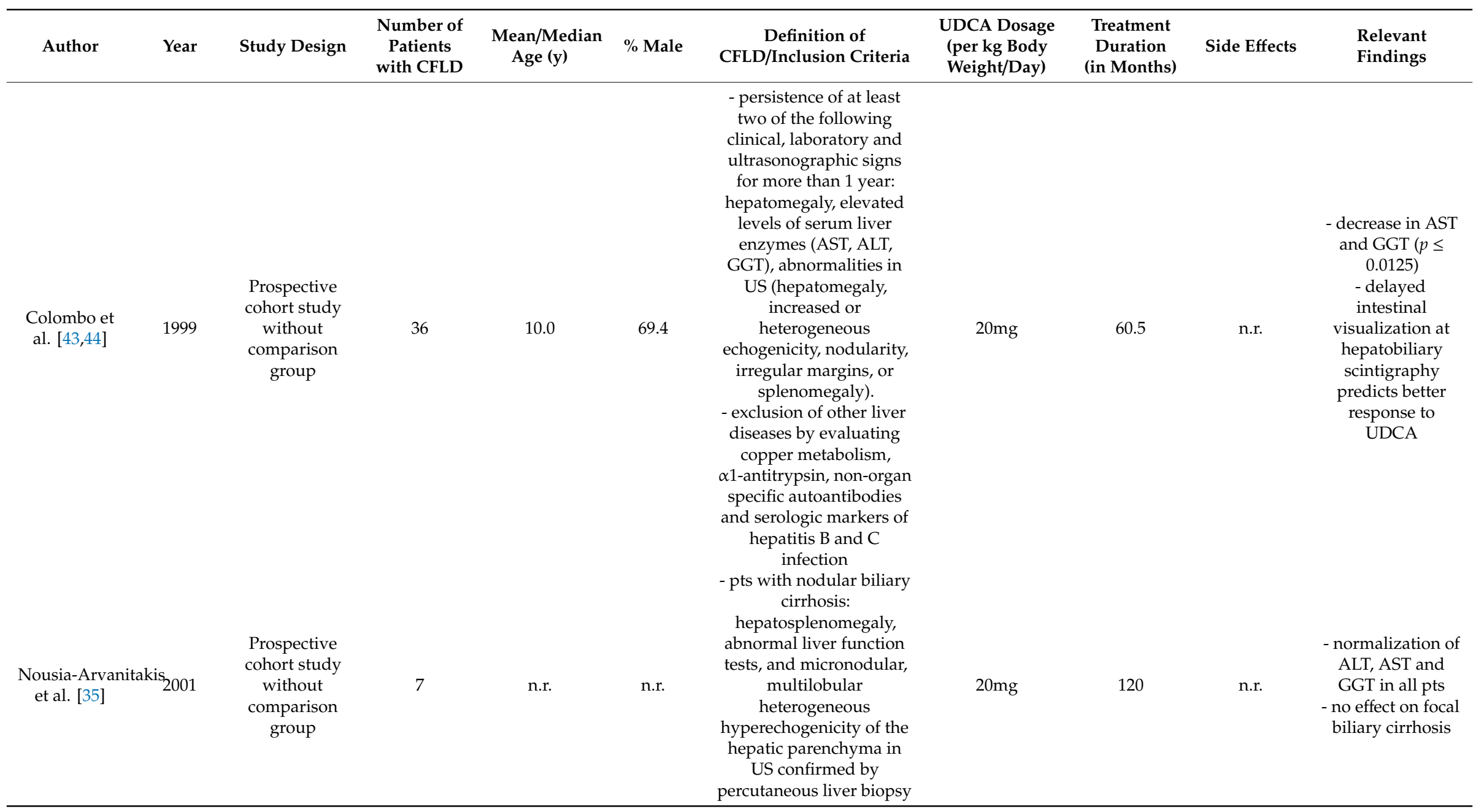


Table 1. Cont.

\begin{tabular}{|c|c|c|c|c|c|c|c|c|c|c|}
\hline Author & Year & Study Design & $\begin{array}{l}\text { Number of } \\
\text { Patients } \\
\text { with CFLD }\end{array}$ & $\begin{array}{l}\text { Mean/Median } \\
\text { Age (y) }\end{array}$ & $\%$ Male & $\begin{array}{l}\text { Definition of CFLD/Inclusion } \\
\text { Criteria }\end{array}$ & $\begin{array}{l}\text { UDCA Dosage } \\
\text { (per kg Body } \\
\text { Weight/Day) }\end{array}$ & $\begin{array}{l}\text { Treatment } \\
\text { Duration } \\
\text { (in Months) }\end{array}$ & $\begin{array}{l}\text { Side } \\
\text { Effects }\end{array}$ & $\begin{array}{l}\text { Relevant } \\
\text { Findings }\end{array}$ \\
\hline $\begin{array}{l}\text { Desmond } \\
\text { et al. } \\
\text { [45] }\end{array}$ & 2007 & $\begin{array}{l}\text { Retrospective } \\
\text { cohort study }\end{array}$ & 22 & n.r. & 63.0 & $\begin{array}{l}\text { - persistent (> } 6 \text { mo) and } \\
\text { significant (> ×2 upper normal } \\
\text { limit) AST, ALT and/or ALP } \\
\text { elevation and/or hepatobiliary } \\
\text { symptoms (pruritus, fatigue or } \\
\text { right upper quadrant pain) } \\
\text { - positive liver histology (focal } \\
\text { biliary cirrhosis or multilobular } \\
\text { cirrhosis), or at least two of the } \\
\text { following parameters on at least } \\
\text { two consecutive examinations } \\
\text { spanning a 1-year period: (i) } \\
\text { clinical hepatomegaly (liver span } \\
\text { 412 cm in the midclavicular line), } \\
\text { confirmed by US; (ii) abnormal } \\
\text { serum liver enzyme levels, } \\
\text { consisting of elevation above the } \\
\text { upper normal limits of two of the } \\
\text { following: AST, ALT, GGT or AP; } \\
\text { and (iii) US abnormalities other } \\
\text { than hepatomegaly (i.e., increased, } \\
\text { heterogeneous echogenicity; } \\
\text { nodularity; irregular margins; } \\
\text { splenomegaly). Ultrasonographic } \\
\text { pattern of steatosis did not } \\
\text { represent a diagnostic criterion. At } \\
\text { both the paediatric hospital and } \\
\text { the adult hospital, patients were } \\
\text { screened for other causes of } \\
\text { abnormal liver enzyme levels (i.e., } \\
\text { hepatitis A, B or C virus; } \\
\text { cytomegalovirus; Epstein-Barr } \\
\text { virus; alcohol; drugs; or toxins) } \\
\text { and were excluded if any of these } \\
\text { were present }\end{array}$ & $\begin{array}{l}10-15 \mathrm{mg} \\
\text { was titrated } \\
\text { upwards } \\
\text { according } \\
\text { to symptomatic } \\
\text { and/or } \\
\text { biochemical } \\
\text { response } \\
\text { (reduction in } \\
\text { liver enzymes to } \\
<\times 1.5 \text { upper } \\
\text { normal } \\
\text { limit) }\end{array}$ & 43.2 & $\begin{array}{l}\text { transient } \\
\text { pruritus } \\
\text { in } 2 \mathrm{pts}\end{array}$ & $\begin{array}{c}\text { - decrease in ALT } \\
(p<0.001), \mathrm{AST} \\
(p=0.005), \mathrm{GGT} \\
(p=0.021) \text { and AP } \\
(p<0.001) \\
\text { - improvement in } \\
\text { hepatobiliary } \\
\text { symptoms } \\
\text { including pruritus, } \\
\text { fatigue and right } \\
\text { upper quadrant } \\
\text { pain }(p=0.0003)\end{array}$ \\
\hline
\end{tabular}


Table 1. Cont.

\begin{tabular}{|c|c|c|c|c|c|c|c|c|c|c|}
\hline Author & Year & Study Design & $\begin{array}{c}\text { Number of } \\
\text { Patients } \\
\text { with CFLD }\end{array}$ & $\begin{array}{l}\text { Mean/Median } \\
\text { Age (y) }\end{array}$ & $\%$ Male & $\begin{array}{c}\text { Definition of } \\
\text { CFLD/Inclusion Criteria }\end{array}$ & $\begin{array}{l}\text { UDCA Dosage } \\
\text { (per kg Body } \\
\text { Weight/Day) }\end{array}$ & $\begin{array}{l}\text { Treatment } \\
\text { Duration } \\
\text { (in Months) }\end{array}$ & Side Effects & $\begin{array}{l}\text { Relevant } \\
\text { Findings }\end{array}$ \\
\hline $\begin{array}{l}\text { Siano et al. } \\
\text { [46] }\end{array}$ & 2010 & $\begin{array}{l}\text { Retrospective } \\
\text { cohort study }\end{array}$ & $\begin{array}{c}26 \\
\text { (14 pts with } \\
\text { early vs. } 12 \\
\text { pts with late } \\
\text { introduction } \\
\text { of UDCA }\end{array}$ & n.r. & $\begin{array}{l}50.0 \text { vs. } \\
75.0\end{array}$ & $\begin{array}{c}\text { - clinical (hepatomegaly), } \\
\text { biochemical (increase of } \\
\text { at least two serum liver } \\
\text { enzyme levels above the } \\
\text { upper normal limit) or } \\
\text { abnormalities in US } \\
\text { (increased echogenicity, } \\
\text { no cirrhosis) recorded on } \\
\text { two consecutive } \\
\text { examinations within a } \\
\text { 3-month period, in the } \\
\text { absence of other possible } \\
\text { causes } \\
\text { - US pattern of steatosis } \\
\text { did not represent a }\end{array}$ & $15 \mathrm{mg}$ & 108 & n.r. & $\begin{array}{c}\text { lower prevalence } \\
\text { of CFLD in early } \\
\text { UDCA group ( } p< \\
0.05)\end{array}$ \\
\hline $\begin{array}{c}\text { Kappler et al. } \\
\text { [47] }\end{array}$ & 2012 & $\begin{array}{l}\text { Retrospective } \\
\text { case-control } \\
\text { study }\end{array}$ & $\begin{array}{l}98 \text { vs. } 98 \text { age- } \\
\text { and } \\
\text { gender-matched } \\
\text { controls } \\
\text { without } \\
\text { CFLD vs. } 9 \\
\text { historical } \\
\text { controls } \\
\text { with CFLD }\end{array}$ & d & 57.1 & $\begin{array}{c}\text { selection criterion } \\
\text { - elevation of one or more } \\
\text { serum liver enzymes } \\
\text { (ALT, AST, GGT, GLDH) } \\
>1.5 \text { upper normal limit } \\
\text { and persisting for }>6 \\
\text { months, or } \\
\text { - liver enlargement }>2 \mathrm{~cm} \\
\text { for }>6 \text { mo } \\
\text { - other potential causes of } \\
\text { liver disease such as } \\
\text { alpha } 1 \text {-antitrypsin } \\
\text { deficiency excluded }\end{array}$ & $20 \mathrm{mg}$ & 86.4 & n.r. & $\begin{array}{l}\text { decrease in ALT, } \\
\text { AST, GGT, GLDH } \\
(p<0.001)\end{array}$ \\
\hline
\end{tabular}


Table 1. Cont.

\begin{tabular}{|c|c|c|c|c|c|c|c|c|c|c|}
\hline Author & Year & Study Design & $\begin{array}{l}\text { Number of } \\
\text { Patients } \\
\text { with CFLD }\end{array}$ & $\begin{array}{l}\text { Mean/Median } \\
\text { Age (y) }\end{array}$ & $\%$ Male & $\begin{array}{c}\text { Definition of } \\
\text { CFLD/Inclusion Criteria }\end{array}$ & $\begin{array}{l}\text { UDCA Dosage } \\
\text { (per kg Body } \\
\text { Weight/Day) }\end{array}$ & $\begin{array}{l}\text { Treatment } \\
\text { Duration } \\
\text { (in Months) }\end{array}$ & Side Effects & $\begin{array}{l}\text { Relevant } \\
\text { Findings }\end{array}$ \\
\hline $\begin{array}{l}\text { Van der Feen } \\
\text { et al. [48] }\end{array}$ & 2016 & $\begin{array}{l}\text { Retrospective } \\
\text { cohort study }\end{array}$ & $\begin{array}{c}32 \text { vs. } 73 \\
\text { patients } \\
\text { without } \\
\text { CFLD }\end{array}$ & 10.3 & 62.5 & $\begin{array}{l}\text { - at least two of the } \\
\text { following conditions } \\
\text { were present: } \\
\text { hepatomegaly confirmed } \\
\text { by US, other } \\
\text { abnormalities of the liver } \\
\text { parenchyma on } \\
\text { ultrasound, e.g., } \\
\text { heterogeneous } \\
\text { echogenicity and } \\
\text { persistently increased } \\
\text { liver enzymes (ASAT, } \\
\text { ALAT, GGT) with at least } \\
\text { two out of these three } \\
\text { being abnormal for at } \\
\text { least } \\
12 \text { mo } \\
\text { - persistently raised } \\
\text { transaminases only } \\
\text { - US examination } \\
\text { consistent with cirrhosis, } \\
\text { i.e., nodular aspect of the } \\
\text { liver and/or a clearly } \\
\text { irregular liver contour } \\
\text { and/or splenomegaly }\end{array}$ & $15-20 \mathrm{mg}$ & 103.2 & n.r. & $\begin{array}{c}\text { - decrease of ALT } \\
(p<0.001), \text { AST } \\
(p<0.01), \text { and } \\
\text { GGT }(p=0.01) \\
\text { - Decrease in liver } \\
\text { stiffness }(p<0.01) \\
\text { in a subgroup of } \\
\text { patients }\end{array}$ \\
\hline
\end{tabular}


Table 1. Cont.

\begin{tabular}{|c|c|c|c|c|c|c|c|c|c|c|}
\hline Author & Year & Study Design & $\begin{array}{c}\text { Number of } \\
\text { Patients } \\
\text { with CFLD }\end{array}$ & $\begin{array}{c}\text { Mean/Median } \\
\text { Age (y) }\end{array}$ & $\%$ Male & $\begin{array}{c}\text { Definition of } \\
\text { CFLD/Inclusion Criteria }\end{array}$ & $\begin{array}{l}\text { UDCA Dosage } \\
\text { (per kg Body } \\
\text { Weight/Day) }\end{array}$ & $\begin{array}{c}\text { Treatment } \\
\text { Duration } \\
\text { (in Months) }\end{array}$ & Side Effects & $\begin{array}{l}\text { Relevant } \\
\text { Findings }\end{array}$ \\
\hline $\begin{array}{l}\text { Boelle et al. } \\
\text { [49] }\end{array}$ & 2019 & $\begin{array}{l}\text { Retrospective } \\
\text { multicentre } \\
\text { cohort study }\end{array}$ & $\begin{array}{l}605 \text { (of these } \\
38 \% \text { under } \\
\text { UDCA at the } \\
\text { age of } 30 \text { ) } \\
\text { vs. } 2723 \\
\text { without } \\
\text { CFLD }\end{array}$ & 17.9 & 56.5 & $\begin{array}{l}\text { - at least two of the } \\
\text { following characteristics } \\
\text { present: (1) abnormal } \\
\text { physical examination } \\
\text { (hepatomegaly and/or } \\
\text { splenomegaly); ( } 2) \\
\text { abnormalities of liver } \\
\text { function tests defined as } \\
\text { an increase of } \\
\text { transaminase (ALT and/or } \\
\text { AST) and/or GGT levels } \\
\text { above the upper normal } \\
\text { limits; (3) US evidence of } \\
\text { liver involvement } \\
\text { (heterogeneous } \\
\text { echogenicity, irregular } \\
\text { margins, or nodularity), } \\
\text { portal hypertension } \\
\text { (splenomegaly, increased } \\
\text { thickness of the lesser } \\
\text { omentum, } \\
\text { spontaneous splenorenal } \\
\text { anastomosis, large } \\
\text { collateral veins, or } \\
\text { ascites), or biliary } \\
\text { abnormalities (bile duct } \\
\text { dilatation) } \\
\text { - cirrhosis, diagnosed by } \\
\text { US, CT, and/or MRI, } \\
\text { and/or portal } \\
\text { hypertension } \\
\text { (splenomegaly, } \\
\text { hypersplenism (platelets } \\
<150 \mathrm{G} / \mathrm{L} \text { and white } \\
\text { blood cells }<3 \mathrm{G} / \mathrm{L} \text { ), } \\
\text { and/or spontaneous } \\
\text { portosystemic shunts on } \\
\text { US) and/or esophageal } \\
\text { varices }\end{array}$ & n.r. & n.r. & n.r. & $\begin{array}{l}\text { che in mean } \\
\text { age at severe } \\
\text { CFLD onset with } \\
\text { UDCA treatment } \\
\text { no evidence of a }\end{array}$ \\
\hline
\end{tabular}


Table 1. Cont.

\begin{tabular}{|c|c|c|c|c|c|c|c|c|c|c|}
\hline Author & Year & Study Design & $\begin{array}{l}\text { Number of } \\
\text { Patients } \\
\text { with CFLD }\end{array}$ & $\begin{array}{l}\text { Mean/Median } \\
\text { Age (y) }\end{array}$ & $\%$ Male & $\begin{array}{c}\text { Definition of } \\
\text { CFLD/Inclusion Criteria }\end{array}$ & $\begin{array}{l}\text { UDCA Dosage } \\
\text { (per kg Body } \\
\text { Weight/Day) }\end{array}$ & $\begin{array}{c}\text { Treatment } \\
\text { Duration } \\
\text { (in Months) }\end{array}$ & Side Effects & $\begin{array}{l}\text { Relevant } \\
\text { Findings }\end{array}$ \\
\hline $\begin{array}{l}\text { Toledano et } \\
\text { al. [16] }\end{array}$ & 2019 & $\begin{array}{l}\text { Retrospective } \\
\text { multicentre } \\
\text { cohort study }\end{array}$ & $\begin{array}{l}1749 \text { on } \\
\text { UDCA vs. } \\
1668 \text { without } \\
\text { UDCA }\end{array}$ & 21.3 & 58.6 & $\begin{array}{c}\text { - elevated liver enzymes } \\
\text { (ALT, AST, or GGT) } \\
\text { - abnormal (but } \\
\text { non-cirrhotic) } \\
\text { appearances in US } \\
\text { including steatosis } \\
\text { - evidence of cirrhosis } \\
\text { in US } \\
\text { - evidence of cirrhosis and } \\
\text { portal hypertension as } \\
\text { evidenced by the } \\
\text { presence of } \\
\text { splenomegaly, ascites or } \\
\text { gastro-oesophageal } \\
\text { varices }\end{array}$ & n.r. & 48 & n.r. & $\begin{array}{c}\text { UDCA in } \\
\text { non-cirrhotic pts } \\
\text { associated with } \\
\text { prolonged overall } \\
\text { survival (HR0.50, } \\
95 \% \text { CI } 0.36-0.69, \\
p<0.0001 \text { ), but } \\
\text { not in cirrhotic pts } \\
\text { (HR 1.19, 95\% CI } \\
0.46-3.10, p=0.71)\end{array}$ \\
\hline
\end{tabular}

ALT, alanine aminotransferase; AST, aspartate amino transferase; AP, alkaline phosphatase; BW, body weight; CT, computed tomography; GGT, gamma glutamyl transpeptidase; GLDH, glutamate dehydrogenase; MRI, magnetic resonance imaging; n.r., not reported; pts, patients; UDCA, ursodeoxycholic acid; US, ultrasound; Tc; technecium. 
For all currently available CFTR modulators in clinics it is recommended to check for liver function test abnormalities (transaminases and bilirubin) on a regular basis, which have been described in about $5 \%$ to $15 \%$ of patients as a potential side effect of these drugs up to $>8$ time the upper limit of normal $[50,54,55]$. However, there is also some evidence that CFTR modulators might have a beneficial effect on the liver. Van de Peppel et al. described that treatment with Ivacaftor partially restored disrupted FGF19-regulated bile acid homeostasis in 117 patients with CFTR gating mutations (partially F508del heterozygoty) participating in the GOAL study, yet these findings did not correlate with CFTR function in other organs, as measured by sweat chloride levels or pulmonary function [56]. Furthermore, mid- and long-term effects on liver function or histology remain unclear. Another study by Gelzo and colleagues reported a beneficial effect of Lumacaftor/Ivacaftor on cholesterol metabolism, enterohepatic flux and improvement of alkaline phosphatase in 40 patients with at least one F508del mutation [57]. A small study including 20 patients with CF, of which nine received Lumacaftor/Ivacaftor, the use of this CFTR modulator combination was associated with less hepatic steatosis as assessed by magnetic resonance imaging proton density fat fraction [58]. In an in vitro study with human derived pluripotent stem cells induced to cholangiocytes, Fiorotto et al. could show that the effect of Lumacaftor/Ivacaftor to correct and potentiate F508del CFTR by a combination with the Src inhibitor PP2 successfully restored fluid secretion to normal levels [21].

Ivacaftor was also hypothesized to be effective in restoring defective phosphatidylcholine secretion in five mutations in the ATP-binding sites of ABCB4, three of which five have been identified as gating mutations in CF (G551D, S1251N, and G1349D) in cell models supplemented by a three-dimensional structural modeling [59].

Finally, Ivacaftor has also shown therapeutic potential in an in vitro model of progressive familial intrahepatic cholestasis type 2 (PFIC2) caused by ABCB11 missense mutations affecting bile salt export pump (BSEP): Ivacaftor treatment increased the taurocholate transport activity of mutated BSEP by 1.7-fold, reaching $95 \%$ of BSEP function [60].

Table 2. Effects of approved Cystic Fibrosis Transmembrane Conductance Regulator modulators on Cystic Fibrosis organ manifestations.

\begin{tabular}{|c|c|c|c|c|c|}
\hline $\begin{array}{c}\text { CFTR } \\
\text { Modulator }\end{array}$ & $\begin{array}{l}\text { Effect on } \\
\text { CFTR }\end{array}$ & $\begin{array}{c}\text { Targeted CFTR } \\
\text { Mutation }\end{array}$ & Effect on the Liver & $\begin{array}{l}\text { Effect on other } \\
\text { Organ Systems }\end{array}$ & References \\
\hline \multirow[t]{3}{*}{$\begin{array}{l}\text { ivacaftor } \\
(\mathrm{VX}-770)\end{array}$} & potentiator & $\begin{array}{c}\text { G551D, G1244E, } \\
\text { G1349D, G178R, } \\
\text { G551S, S1251N, } \\
\text { S1255P, S549N und } \\
\text { S549R }\end{array}$ & $\begin{array}{c}\text { Increase in ALT } \\
(13.2 \%), \text { AST }(9.6 \%) \\
\text { and bilirubin }(2.4 \%)> \\
2 x \text { to }>8 x \text { ULN }\end{array}$ & $\begin{array}{c}\text { Significant } \\
\text { improvement in } \\
\text { FEV1\% after } 24 \text { and } \\
48 \text { weeks } \\
\text { Significant reduction } \\
\text { of pulmonary } \\
\text { exacerbations } \\
\text { Significant increase } \\
\text { in body weight }\end{array}$ & $\begin{array}{c}\text { [54] } \\
\text { (adults) }\end{array}$ \\
\hline & & & $\begin{array}{c}\text { Elevate of liver } \\
\text { function test }>8 \times \text { ULN } \\
(15 \%)\end{array}$ & $\begin{array}{c}\text { significant } \\
\text { improvement in } \\
\text { FEV1\% after } 24 \text { and } \\
48 \text { weeks } \\
\text { significant reduction } \\
\text { of pulmonary } \\
\text { exacerbations, } \\
\text { significant increase } \\
\text { in body weight }\end{array}$ & $\begin{array}{c}\text { [55] } \\
\text { (small } \\
\text { children) }\end{array}$ \\
\hline & & & $\begin{array}{c}\text { rescue of } \\
\text { disease-causing } \\
\text { variations in } \\
\text { ATP-binding sites of } \\
\text { ABCB4 that cause } \\
\text { defects in } \\
\text { phosphatidylcholine } \\
\text { secretion relevant to } \\
\text { bile composition }\end{array}$ & & [59] \\
\hline
\end{tabular}


Table 2. Cont.

\begin{tabular}{|c|c|c|c|c|c|}
\hline $\begin{array}{c}\text { CFTR } \\
\text { Modulator }\end{array}$ & $\begin{array}{l}\text { Effect on } \\
\text { CFTR }\end{array}$ & $\begin{array}{l}\text { Targeted CFTR } \\
\text { Mutation }\end{array}$ & Effect on the Liver & $\begin{array}{l}\text { Effect on other } \\
\text { Organ Systems }\end{array}$ & References \\
\hline \multirow[t]{4}{*}{$\begin{array}{c}\text { ivacaftor/ } \\
\text { tezacaftor/ } \\
\text { elexacaftor } \\
\text { (VX-770/Vx-661/ } \\
\text { VX-445 }\end{array}$} & $\begin{array}{l}\text { potentiator/ } \\
\text { corrector/ } \\
\text { corrector }\end{array}$ & $\begin{array}{c}\text { Hetero- and } \\
\text { homozygous F508del }\end{array}$ & $\begin{array}{c}\text { Increased liver } \\
\text { enzymes }(8 \%) \text { and } \\
\text { bilirubin }(3 \%)>2 x \\
\text { ULN }\end{array}$ & $\begin{array}{c}\text { Significant increase } \\
\text { in FEV1\% through } \\
\text { day } 29\end{array}$ & [50] \\
\hline & & & $\begin{array}{l}\text { restores FGF19 } \\
\text { regulated bile acid } \\
\text { homeostasis }\end{array}$ & & [56] \\
\hline & & & & $\begin{array}{l}\text { increase in small } \\
\text { intestinal } \mathrm{pH}\end{array}$ & [61] \\
\hline & & & & $\begin{array}{c}\text { increase in } \\
\text { Akkermansia, } \\
\text { decrease in intestinal } \\
\text { inflammation }\end{array}$ & [62] \\
\hline \multirow[t]{2}{*}{$\begin{array}{c}\text { ivacaftor/ } \\
\text { lumacaftor } \\
\text { (VX-770/VX-809) }\end{array}$} & $\begin{array}{l}\text { potentiator/ } \\
\text { corrector }\end{array}$ & $\begin{array}{l}\text { Homozygous } \\
\text { F508del }\end{array}$ & $\begin{array}{c}\text { One patient } \\
\text { discontinued } \\
\text { treatment because of } \\
\text { abnormal liver } \\
\text { function tests (before } \\
\text { taking lumacaftor) }\end{array}$ & $\begin{array}{c}\text { Significant } \\
\text { improvement in } \\
\text { FEV1\% after } 56 \text { days }\end{array}$ & [63] \\
\hline & & & $\begin{array}{l}\text { significantly lower } \\
\text { hepatic steatosis } \\
\text { measured by magnetic } \\
\text { resonance imaging } \\
\text { proton density fat } \\
\text { fraction }\end{array}$ & & [58] \\
\hline \multirow[t]{3}{*}{$\begin{array}{c}\text { ivacaftor/ } \\
\text { tezacaftor } \\
\text { (VX-770/VX-661) }\end{array}$} & $\begin{array}{l}\text { potentiator/ } \\
\text { corrector }\end{array}$ & $\begin{array}{c}\text { Hetero- and } \\
\text { homozygous F508del }\end{array}$ & $\begin{array}{c}\text { Elevation of } \\
\text { transaminases }>3 x \\
\text { ULN }(0.6 \%) \\
\text { Elevation of bilirubin } \\
>2 x \text { ULN }(1.2 \%)\end{array}$ & $\begin{array}{c}\text { significant } \\
\text { improvement in } \\
\text { FEV1\% after } 56 \text { days }\end{array}$ & [64] \\
\hline & & $\begin{array}{l}\text { Heterozygous } \\
\text { F508del }\end{array}$ & & $\begin{array}{c}\text { significant } \\
\text { improvement in } \\
\text { FEV1\% after } 8 \text { weeks }\end{array}$ & [65] \\
\hline & & & $\begin{array}{c}\text { increase in } \\
\text { aminotransferase } \\
\text { concentrations }(12 \%) \\
>3 x \text { to }>5 x \text { ULN }\end{array}$ & $\begin{array}{l}\text { significant increase } \\
\text { in FEV1\% through } \\
\text { week } 4, \\
\text { significant increase } \\
\text { in body weight }\end{array}$ & [52] \\
\hline
\end{tabular}

In summary, CFTR modulators show a certain therapeutic potential in CFLD, but there is still a long way to go and we are just at the beginning. We need to learn more about the mechanisms underlying hepatic toxicity as well as improvement of liver alterations by CFTR modulators in order to select patients who may benefit. This evolution might be inhibited by the fact that there is no clear association of CFLD with genetic mutations, and that a unified definition of CFLD based on its pathomechanism and pathophysiology is currently lacking. Thus, to date the therapeutic response to CFTR modulators seems unpredictable.

\section{Effects of Gene Therapies on CFLD}

In contrast to CFTR modulators, which partially restore CFTR protein function, CFTR targeting gene therapies establish a new, correct version of the CFTR gene in order to produce normally functioning CFTR protein. In contrast to CFTR modulators, gene therapy bears the advantage that patients may be treated independently of the underlying CFTR mutation.

A randomized controlled trial (phase 2b) investigated a nebulized pGM169/GL67A gene-liposome complex delivering plasmid DNA encoding the CFTR gene to the lungs and demonstrated a significant, 
but modest effect on FEV1\% after 1 year of monthly application [66]. Notably, this non-integrating gene therapy had no negative effect on liver enzymes. However, the improvement of lung function was lower in comparison to those achieved with CFTR modulators, so that the substance did not reach clinical application.

Another approach is to use messenger ribonucleic acid (mRNA)-based treatments, such as MRT-5005, to deliver the correct mRNA to lung epithelial cells in order to produce functional CFTR protein. Currently, a clinical phase1/2 trial (NCT03375047, RESTORE-CF) is underway.

Further possibilities evolve by the use of clustered regulatory interspaced short palindrome repeats (CRISPR)/Cas9 to repair defective CFTR in vitro and in vivo [67-69], but have not been tested in models of CFLD or humans so far.

\section{Conclusions and Future Treatment Options}

There has been tremendous effort and progress in the treatment of CF within the last years. Due to the favorable epidemiologic evolution we have to face increasing numbers of patients suffering from CFLD. However, to date, an efficient causative therapy is lacking.

Besides the evolution of CFTR modulators restoring CFTR protein function, substances creating an additive effect, such as Src inhibitors targeting the TLR-4-mediated inflammatory processes at the bile duct epithelium could be a future treatment option, but have not been investigated in humans. Furthermore, molecules involved in CFTR ubiquitylation that function as regulators of CFTR stability and degradation have been discussed as promising therapeutic targets [70]. Mesenchymal stromal cells and induced pluripotent stem cells have been investigated in CF lung disease in vitro and in vivo, but have not been investigated in CFLD so far [71]. Finally, antifibrotic substances such as Farnesoid X Receptor (FXR) agonists, which target both the gut and the liver, and are centrally involved in bile acid homeostasis might be interesting candidates in the treatment of CFLD, but have not been investigated in this indication [72].

Funding: This research received no external funding.

Conflicts of Interest: The authors declare no conflict of interest.

\section{Abbreviations}

$\begin{array}{ll}\text { CF } & \text { Cystic Fibrosis } \\ \text { CFLD } & \text { Cystic Fibrosis-related liver disease } \\ \text { CFTR } & \text { cystic fibrosis transmembrane conductance regulator } \\ \text { ABC } & \text { ATP-binding cassette } \\ \text { ABCC7 } & \text { ABC subfamily C member 7 } \\ \text { AST } & \text { aspartate amino transaminase } \\ \text { ALT } & \text { alanine amino transaminase } \\ \text { GGT } & \text { gamma glutamyl transferase } \\ \text { CFRD } & \text { Cystic Fibrosis-related diabetes mellitus } \\ \text { TLR4 } & \text { toll-like receptor 4 } \\ & \text { Solute carrier family 33 acetyl-coenzyme A } \\ \text { SLC33A1 } & \text { transporter member 1 } \\ \text { GPNMB } & \text { glycoprotein NMB } \\ \text { NCF2 } & \text { neutrophil cytosolic Factor 2 } \\ \text { RASGRP1 } & \text { RAS guanyl nucleotide-releasing protein 1 } \\ \text { LGALS3 } & \text { lectin galactosidase-binding soluble 3 } \\ \text { PTPN13 } & \text { protein-tyrosine phosphatase nonreceptor-type 13 } \\ \text { UDCA } & \text { ursodeoxycholic acid } \\ \text { BW } & \text { body weight } \\ \text { FEV1 } & \text { forced expiratory volume in one second } \\ \text { FXR } & \text { Farnesoid X Receptor }\end{array}$




\section{References}

1. Ratjen, F.; Bell, S.C.; Rowe, S.M.; Goss, C.H.; Quittner, A.L.; Bush, A. Cystic fibrosis. Nat. Rev. Dis. Primers 2015, 1, 15010. [CrossRef] [PubMed]

2. Elborn, S.; Woodhead, M. Cystic fibrosis. Respir. Infect. 2006, 388, 401-421. [CrossRef]

3. Cystic Fibrosis Mutation Database.

4. Beuers, U.; Hohenester, S.; Wenniger, L.J.M.D.B.; Kremer, A.E.; Jansen, P.L.M.; Elferink, R.P.J.O. The biliary HCO3- umbrella: A unifying hypothesis on pathogenetic and therapeutic aspects of fibrosing cholangiopathies. Hepatology 2010, 52, 1489-1496. [CrossRef] [PubMed]

5. Peters, N.; Dichgans, M.; Surendran, S.; Argilés, J.M.; López-Soriano, F.J.; Busquets, S.; Dittmann, K.; Rodemann, H.P.; Sindrilaru, A.; Sunderkötter, C.; et al. Cystic Fibrosis. Encycl. Mol. Mech. Dis. 2009, 373, 482-483. [CrossRef]

6. Estabrooks, S.; Brodsky, J.L. Regulation of CFTR Biogenesis by the Proteostatic Network and Pharmacological Modulators. Int. J. Mol. Sci. 2020, 21, 452. [CrossRef]

7. Dodge, J.A.; Lewis, P.A.; Stanton, M.; Wilsher, J. Cystic fibrosis mortality and survival in the UK: 1947-2003. Eur. Respir. J. 2007, 29, 522-526. [CrossRef]

8. Chryssostalis, A.; Hubert, D.; Coste, J.; Kanaan, R.; Burgel, P.-R.; Desmazes-Dufeu, N.; Soubrane, O.; Dusser, D.; Sogni, P. Liver disease in adult patients with cystic fibrosis: A frequent and independent prognostic factor associated with death or lung transplantation. J. Hepatol. 2011, 55, 1377-1382. [CrossRef]

9. Pugsley, H.E.; Spence, P.M. A Case of Cystic Fibrosis of The Pancreas Associated with Chronic Pulmonary Disease and Cirrhosis of The Liver. Ann. Intern. Med. 1949, 30, 1262-1272. [CrossRef]

10. Debray, D.; Kelly, D.; Houwen, R.; Strandvik, B.; Colombo, C. Best practice guidance for the diagnosis and management of cystic fibrosis-associated liver disease. J. Cyst. Fibros. 2011, 10, S29-S36. [CrossRef]

11. Koh, C.; Sakiani, S.; Surana, P.; Zhao, X.; Eccleston, J.; Kleiner, D.E.; Herion, D.; Liang, T.J.; Hoofnagle, J.H.; Chernick, M.; et al. Adult-onset cystic fibrosis liver disease: Diagnosis and characterization of an underappreciated entity. Hepatology 2017, 66, 591-601. [CrossRef]

12. Stonebraker, J.R.; Ooi, C.Y.; Pace, R.G.; Corvol, H.; Knowles, M.R.; Durie, P.R.; Ling, S.C. Features of Severe Liver Disease With Portal Hypertension in Patients With Cystic Fibrosis. Clin. Gastroenterol. Hepatol. 2016, 14, 1207-1215.e3. [CrossRef] [PubMed]

13. Colombo, C.; Battezzati, P.M.; Crosignani, A.; Morabito, A.; Costantini, D.; Padoan, R.; Giunta, A. Liver disease in cystic fibrosis: A prospective study on incidence, risk factors, and outcome. Hepatology 2002, 36, 1374-1382. [CrossRef] [PubMed]

14. Lamireau, T.; Monnereau, S.; Martin, S.; Marcotte, J.-E.; Winnock, M.; Alvarez, F. Epidemiology of liver disease in cystic fibrosis: a longitudinal study. J. Hepatol. 2004, 41, 920-925. [CrossRef] [PubMed]

15. Bartlett, J.R. Genetic Modifiers of Liver Disease in Cystic Fibrosis. JAMA 2009, 302, 1076-1083. [CrossRef] [PubMed]

16. Toledano, M.B.; Mukherjee, S.K.; Howell, J.; Westaby, D.; Khan, S.A.; Bilton, D.; Simmonds, N.J. The emerging burden of liver disease in cystic fibrosis patients: A UK nationwide study. PLoS ONE 2019, 14, e0212779. [CrossRef]

17. Staufer, K.; Halilbasic, E.; Trauner, M.; Kazemi-Shirazi, L. Cystic Fibrosis Related Liver Disease-Another Black Box in Hepatology. Int. J. Mol. Sci. 2014, 15, 13529-13549. [CrossRef]

18. Rowntree, R.K.; Harris, A. The Phenotypic Consequences of CFTR Mutations. Ann. Hum. Genet. 2003, 67, 471-485. [CrossRef]

19. Kinnman, N.; Lindblad, A.; Housset, C.; Buentke, E.; Scheynius, A.; Strandvik, B.; Hultcrantz, R. Expression of cystic fibrosis transmembrane conductance regulator in liver tissue from patients with cystic fibrosis. Hepatology 2000, 32, 334-340. [CrossRef]

20. Fiorotto, R.; Villani, A.; Kourtidis, A.; Scirpo, R.; Amenduni, M.; Geibel, P.J.; Cadamuro, M.; Spirli, C.; Anastasiadis, P.Z.; Strazzabosco, M. The cystic fibrosis transmembrane conductance regulator controls biliary epithelial inflammation and permeability by regulating Src tyrosine kinase activity. Hepatology 2016, 64, 2118-2134. [CrossRef]

21. Fiorotto, R.; Amenduni, M.; Mariotti, V.; Fabris, L.; Spirli, C.; Strazzabosco, M. Src kinase inhibition reduces inflammatory and cytoskeletal changes in DeltaF508 human cholangiocytes and improves cystic fibrosis transmembrane conductance regulator correctors efficacy. Hepatology 2018, 67, 972-988. [CrossRef] 
22. Callea, F.; Fevery, J.; Massi, G.; De Groote, J.; Desmet, V.J. Storage of alpha-1-antitrypsin in intrahepatic bile duct cells in alpha-1-antitrypsin deficiency (Pi Z phenotype). Histopathology 1985, 9, 99-108. [CrossRef] [PubMed]

23. Debray, D.; Corvol, H.; Housset, C. Modifier genes in cystic fibrosis-related liver disease. Curr. Opin. Gastroenterol. 2019, 35, 88-92. [CrossRef] [PubMed]

24. Trouvé, P.; Genin, E.; Férec, C. In silico search for modifier genes associated with pancreatic and liver disease in Cystic Fibrosis. PLoS ONE 2017, 12, e0173822. [CrossRef]

25. Sokol, R.J.; Durie, P.R. Recommendations for Management of Liver and Biliary Tract Disease in Cystic Fibrosis. J. Pediatr. Gastroenterol. Nutr. 1999, 28, S1-S13. [CrossRef]

26. Sokol, R.J. Fat-soluble vitamins and their importance in patients with cholestatic liver diseases. Gastroenterol. Clin. North Am. 1994, 23, 673-705.

27. De Franchis, R. Expanding consensus in portal hypertension. J. Hepatol. 2015, 63, 743-752. [CrossRef]

28. Angeli, P.; Bernardi, M.; Villanueva, C.; Francoz, C.; Mookerjee, R.P.; Trebicka, J.; Krag, A.; Laleman, W.; Gines, P. EASL Clinical Practice Guidelines for the management of patients with decompensated cirrhosis. J. Hepatol. 2018, 69, 406-460. [CrossRef]

29. Witters, P.; Libbrecht, L.; Roskams, T.; De Boeck, K.; Dupont, L.; Proesmans, M.; Vermeulen, F.; Maleux, G.; Monbaliu, D.; Pirenne, J.; et al. Liver disease in cystic fibrosis presents as non-cirrhotic portal hypertension. J. Cyst. Fibros. 2017, 16, e11-e13. [CrossRef]

30. Witters, P.; Libbrecht, L.; Roskams, T.; De Boeck, K.; Dupont, L.; Proesmans, M.; Vermeulen, F.; Strandvik, B.; Lindblad, A.; Stephenne, X.; et al. Noncirrhotic presinusoidal portal hypertension is common in cystic fibrosis-associated liver disease. Hepatology 2011, 53, 1064-1065. [CrossRef]

31. Wu, H.; Vu, M.; Dhingra, S.; Ackah, R.; Goss, J.A.; Rana, A.; Quintanilla, N.; Patel, K.; Leung, D.H. Obliterative Portal Venopathy Without Cirrhosis Is Prevalent in Pediatric Cystic Fibrosis Liver Disease With Portal Hypertension. Clin. Gastroenterol. Hepatol. 2019, 17, 2134-2136. [CrossRef]

32. Cotting, J.; Lentze, M.J.; Reichen, J. Effects of ursodeoxycholic acid treatment on nutrition and liver function in patients with cystic fibrosis and longstanding cholestasis. Gut 1990, 31, 918-921. [CrossRef] [PubMed]

33. Colombo, C.; Setchell, K.D.; Podda, M.; Crosignani, A.; Roda, A.; Curcio, L.; Ronchi, M.; Giunta, A. Effects of ursodeoxycholic acid therapy for liver disease associated with cystic fibrosis. J. Pediatr. 1990, 117, 482-489. [CrossRef]

34. Cheng, K.; Ashby, D.; Smyth, R.L. Ursodeoxycholic acid for cystic fibrosis-related liver disease. Cochrane Database Syst. Rev. 2017, 2017, CD000222. [CrossRef] [PubMed]

35. Colombo, C.; Battezzati, P.M.; Podda, M.; Bettinardi, N.; Giunta, A. Ursodeoxycholic acid for liver disease associated with cystic fibrosis: A double-blind multicenter trial. The Italian Group for the Study of Ursodeoxycholic Acid in Cystic Fibrosis. Hepatology 1996, 23, 1484-1490. [CrossRef]

36. Lepage, G.; Paradis, K.; Lacaille, F.; Sénéchal, L.; Ronco, N.; Champagne, J.; Lenaerts, C.; Roy, C.C.; Rasquin-Weber, A. Ursodeoxycholic acid improves the hepatic metabolism of essential fatty acids and retinol in children with cystic fibrosis. J. Pediatr. 1997, 130, 52-58. [CrossRef]

37. Colombo, C.; Castellani, M.R.; Balistreri, W.F.; Seregni, E.; Assaisso, M.L.; Giunta, A. Scintigraphic documentation of an improvement in hepatobiliary excretory function after treatment with ursodeoxycholic acid in patients with cystic fibrosis and associated liver disease. Hepatology 1992, 15, 677-684. [CrossRef]

38. Galabert, C.; Montet, J.; Lengrand, D.; Lecuire, A.; Sotta, C.; Figarella, C.; Chazalette, J. Effects of ursodeoxycholic acid on liver function in patients with cystic fibrosis and chronic cholestasis. J. Pediatr. 1992, 121, 138-141. [CrossRef]

39. Colombo, C.; Crosignani, A.; Assaisso, M.; Battezzati, P.M.; Podda, M.; Giunta, A.; Zimmer-Nechemias, L.; Setchell, K.D.R. Ursodeoxycholic acid therapy in cystic fibrosis—associated liver disease: A dose-response study. Hepatology 1992, 16, 924-930. [CrossRef]

40. O’Brien, S.M.; Campbell, G.R.; Burke, A.F.; Maguire, O.C.; Rowlands, B.J.; Fitzgerald, M.X.; Hegarty, J.E. Serum bile acids and ursodeoxycholic acid treatment in cystic fibrosis-related liver disease. Eur. J. Gastroenterol. Hepatol. 1996, 8, 477-483.

41. Van De Meeberg, P.C.; Houwen, R.H.J.; Sinaasappel, M.; Heijerman, H.G.M.; Bijleveld, C.M.A.; Vanberge-Henegouwen, G.P. Low-dose versus high-dose ursodeoxycholic acid in cystic fibrosis-related cholestatic liver disease. Results of a randomized study with 1-year follow-up. Scand. J. Gastroenterol. 1997, 32, 369-373. [CrossRef] 
42. Lindblad, A.; Glaumann, H.; Strandvik, B. A two-year prospective study of the effect of ursodeoxycholic acid on urinary bile acid excretion and liver morphology in cystic fibrosis-associated liver disease. Hepatology 1998, 27, 166-174. [CrossRef] [PubMed]

43. Colombo, C.; Crosignani, A.; Battezzati, P.M.; Castellani, M.R.; Comi, S.; Melzi, M.L.; Giunta, A. Delayed intestinal visualization at hepatobiliary scintigraphy is associated with response to long-term treatment with ursodeoxycholic acid in patients with cystic fibrosis-associated liver disease. J. Hepatol. 1999, 31, 672-677. [CrossRef]

44. Nousia-Arvanitakis, S.; Fotoulaki, M.; Economou, H.; Xefteri, M.; Galli-Tsinopoulou, A. Long-term Prospective Study of the Effect of Ursodeoxycholic Acid on Cystic Fibrosis-related Liver Disease. J. Clin. Gastroenterol. 2001, 32, 324-328. [CrossRef] [PubMed]

45. Desmond, C.P.; Wilson, J.; Bailey, M.; Clark, D.; Roberts, S.K. The benign course of liver disease in adults with cystic fibrosis and the effect of ursodeoxycholic acid. Liver Int. 2007, 27, 1402-1408. [CrossRef] [PubMed]

46. Siano, M.; De Gregorio, F.; Boggia, B.; Sepe, A.; Ferri, P.; Buonpensiero, P.; Di Pasqua, A.; Raia, V. Ursodeoxycholic acid treatment in patients with cystic fibrosis at risk for liver disease. Dig. Liver Dis. 2010, 42, 428-431. [CrossRef] [PubMed]

47. Kappler, M.; Espach, C.; Schweiger-Kabesch, A.; Lang, T.; Hartl, D.; Hector, A.; Glasmacher, C.; Griese, M. Ursodeoxycholic acid therapy in cystic fibrosis liver disease - a retrospective long-term follow-up case-control study. Aliment. Pharmacol. Ther. 2012, 36, 266-273. [CrossRef] [PubMed]

48. Van Der Feen, C.; Van Der Doef, H.P.; Van Der Ent, C.K.; Houwen, R.H.J. Ursodeoxycholic acid treatment is associated with improvement of liver stiffness in cystic fibrosis patients. J. Cyst. Fibros. 2016, 15, 834-838. [CrossRef]

49. Boëlle, P.-Y.; on behalf of the French CF Modifier Gene Study Investigators; Debray, D.; Guillot, L.; Corvol, H. SERPINA1 Z allele is associated with cystic fibrosis liver disease. Genet. Med. 2019, 21, 2151-2155. [CrossRef]

50. Keating, D.; Marigowda, G.; Burr, L.; Daines, C.; Mall, M.A.; McKone, E.F.; Ramsey, B.W.; Rowe, S.M.; Sass, L.A.; Tullis, E.; et al. VX-445-Tezacaftor-Ivacaftor in Patients with Cystic Fibrosis and One or Two Phe508del Alleles. N. Engl. J. Med. 2018, 379, 1612-1620. [CrossRef]

51. Middleton, P.G.; Mall, M.A.; Dřevínek, P.; Lands, L.C.; McKone, E.F.; Polineni, D.; Ramsey, B.W.; Taylor-Cousar, J.L.; Tullis, E.; Vermeulen, F.; et al. Elexacaftor-Tezacaftor-Ivacaftor for Cystic Fibrosis with a Single Phe508del Allele. N. Engl. J. Med. 2019, 381, 1809-1819. [CrossRef]

52. Heijerman, H.G.M.; McKone, E.F.; Downey, D.G.; Van Braeckel, E.; Rowe, S.M.; Tullis, E.; Mall, M.A.; Welter, J.J.; Ramsey, B.W.; McKee, C.M.; et al. Efficacy and safety of the elexacaftor plus tezacaftor plus ivacaftor combination regimen in people with cystic fibrosis homozygous for the F508del mutation: A double-blind, randomised, phase 3 trial. Lancet 2019, 394, 1940-1948. [CrossRef]

53. Chandra, A.; Garthwaite, C.; Stern, A.D. Characterizing the Drug Development Pipeline for Precision Medicines. Available online: https://www.cff.org/Trials/pipeline (accessed on 18 September 2020).

54. Ramsey, B.W.; Davies, J.; McElvaney, N.G.; Tullis, E.; Bell, S.C.; Dřevínek, P.; Griese, M.; McKone, E.F.; Wainwright, C.E.; Konstan, M.W.; et al. A CFTR Potentiator in Patients with Cystic Fibrosis and theG551DMutation. N. Engl. J. Med. 2011, 365, 1663-1672. [CrossRef] [PubMed]

55. Davies, J.C.; Cunningham, S.; Harris, W.T.; Lapey, A.; Regelmann, W.E.; Sawicki, G.S.; Southern, K.W.; Robertson, S.; Green, Y.; Cooke, J.; et al. Safety, pharmacokinetics, and pharmacodynamics of ivacaftor in patients aged $2-5$ years with cystic fibrosis and a CFTR gating mutation (KIWI): An open-label, single-arm study. Lancet Respir. Med. 2016, 4, 107-115. [CrossRef]

56. Van De Peppel, I.P.; Doktorova, M.; Berkers, G.; De Jonge, H.R.; Houwen, R.H.; Verkade, H.J.; Jonker, J.W.; Bodewes, F.A.J.A. IVACAFTOR restores FGF19 regulated bile acid homeostasis in cystic fibrosis patients with an S1251N or a G551D gating mutation. J. Cyst. Fibros. 2019, 18, 286-293. [CrossRef] [PubMed]

57. Gelzo, M.; Iacotucci, P.; Caputo, M.; Cernera, G.; Comegna, M.; Carnovale, V.; Corso, G.; Castaldo, G. Lumacaftor/ivacaftor improves liver cholesterol metabolism but does not influence hypocholesterolemia in patients with cystic fibrosis. J. Cyst. Fibros. 2020. [CrossRef]

58. Kutney, K.; Donnola, S.B.; A Flask, C.; Gubitosi-Klug, R.; O’Riordan, M.; Mcbennett, K.; Sferra, T.J.; Kaminski, B. Lumacaftor/ivacaftor therapy is associated with reduced hepatic steatosis in cystic fibrosis patients. World J. Hepatol. 2019, 11, 761-772. [CrossRef]

59. Delaunay, J.; Bruneau, A.; Hoffmann, B.; Durand-Schneider, A.; Barbu, V.; Jacquemin, E.; Maurice, M.; Housset, C.; Callebaut, I.; Aït-Slimane, T. Functional defect of variants in the adenosine triphosphate-binding 
sites of $\mathrm{ABCB} 4$ and their rescue by the cystic fibrosis transmembrane conductance regulator potentiator, ivacaftor (VX-770). Hepatology 2016, 65, 560-570. [CrossRef]

60. Mareux, E.; Lapalus, M.; Amzal, R.; Almes, M.; Aït-Slimane, T.; Delaunay, J.-L.; Adnot, P.; Collado-Hilly, M.; Spraul, A.; Falguières, T.; et al. Functional rescue of an ABCB11 mutant by ivacaftor: A new targeted pharmacotherapy approach in bile salt export pump deficiency. Liver Int. 2020, 40, 1917-1925. [CrossRef]

61. Gelfond, D.; Heltshe, S.; Ma, C.; Rowe, S.M.; Frederick, C.; Uluer, A.; Sicilian, L.; Konstan, M.; Tullis, E.; Roach, C.R.N.; et al. Impact of CFTR Modulation on Intestinal pH, Motility, and Clinical Outcomes in Patients With Cystic Fibrosis and the G551D Mutation. Clin. Transl. Gastroenterol. 2017, 8, e81. [CrossRef]

62. Ooi, C.Y.; Syed, S.A.; Rossi, L.; Garg, M.; Needham, B.; Avolio, J.; Young, K.; Surette, M.G.; Gonska, T. Impact of CFTR modulation with Ivacaftor on Gut Microbiota and Intestinal Inflammation. Sci Rep. 2018, 8, 17834. [CrossRef]

63. Boyle, M.P.; Bell, S.C.; Konstan, M.W.; McColley, S.A.; Rowe, S.M.; Rietschel, E.; Huang, X.; Waltz, D.; Patel, N.R.; Rodman, D. A CFTR corrector (lumacaftor) and a CFTR potentiator (ivacaftor) for treatment of patients with cystic fibrosis who have a phe508del CFTR mutation: a phase 2 randomised controlled trial. Lancet Respir. Med. 2014, 2, 527-538. [CrossRef]

64. Donaldson, S.H.; Pilewski, J.M.; Griese, M.; Cooke, J.; Viswanathan, L.; Tullis, E.; Davies, J.C.; Lekstrom-Himes, J.A.; Wang, L.T. Tezacaftor/Ivacaftor in Subjects with Cystic Fibrosis and F508del/F508del-CFTR or F508del/G551D-CFTR. Am. J. Respir. Crit. Care Med. 2018, 197, $214-224$. [CrossRef] [PubMed]

65. Rowe, S.M.; Daines, C.; Ringshausen, F.C.; Kerem, E.; Wilson, J.; Tullis, E.; Nair, N.; Simard, C.; Han, L.; Ingenito, E.P.; et al. Tezacaftor-Ivacaftor in Residual-Function Heterozygotes with Cystic Fibrosis. N. Engl. J. Med. 2017, 377, 2024-2035. [CrossRef] [PubMed]

66. Alton, E.W.F.W.; Armstrong, D.K.; Ashby, D.; Bayfield, K.J.; Bilton, D.; Bloomfield, E.V.; Boyd, A.C.; Brand, J.; Buchan, R.; Calcedo, R.; et al. Repeated nebulisation of non-viral CFTR gene therapy in patients with cystic fibrosis: a randomised, double-blind, placebo-controlled, phase 2b trial. Lancet Respir. Med. 2015, 3, 684-691. [CrossRef]

67. Schwank, G.; Koo, B.-K.; Sasselli, V.; Dekkers, J.F.; Heo, I.; Demircan, T.; Sasaki, N.; Boymans, S.; Cuppen, E.; Van Der Ent, C.K.; et al. Functional Repair of CFTR by CRISPR/Cas9 in Intestinal Stem Cell Organoids of Cystic Fibrosis Patients. Cell Stem Cell 2013, 13, 653-658. [CrossRef]

68. Fan, Z.; Perisse, I.V.; Cotton, C.U.; Regouski, M.; Meng, Q.; Domb, C.; Van Wettere, A.J.; Wang, Z.; Harris, A.; White, K.L.; et al. A sheep model of cystic fibrosis generated by CRISPR/Cas9 disruption of the CFTR gene. JCI Insight 2018, 3. [CrossRef]

69. Crane, A.M.; Kramer, P.; Bui, J.H.; Chung, W.J.; Li, X.S.; Gonzalez-Garay, M.L.; Hawkins, F.; Liao, W.; Mora, D.; Choi, S.; et al. Targeted Correction and Restored Function of the CFTR Gene in Cystic Fibrosis Induced Pluripotent Stem Cells. Stem Cell Rep. 2015, 4, 569-577. [CrossRef]

70. Fukuda, R.; Okiyoneda, T. Cystic Fibrosis Transmembrane Conductance Regulator (CFTR) Ubiquitylation as a Novel Pharmaceutical Target for Cystic Fibrosis. Pharmaceuticals 2020, 13, 75. [CrossRef]

71. Duchesneau, P.; Waddell, T.K.; Karoubi, G. Cell-Based Therapeutic Approaches for Cystic Fibrosis. Int. J. Mol. Sci. 2020, 21, 5219. [CrossRef]

72. Albillos, A.; De Gottardi, A.; Rescigno, M. The gut-liver axis in liver disease: Pathophysiological basis for therapy. J. Hepatol. 2020, 72, 558-577. [CrossRef]

Publisher's Note: MDPI stays neutral with regard to jurisdictional claims in published maps and institutional affiliations.

(C) 2020 by the author. Licensee MDPI, Basel, Switzerland. This article is an open access article distributed under the terms and conditions of the Creative Commons Attribution (CC BY) license (http://creativecommons.org/licenses/by/4.0/). 